\title{
Hearing loss and risk of falls in elderly
}

Letícia R Baraky ${ }^{1}$, Natália B Vasconcelos ${ }^{2 *}$, Ingrid deM Ribeiro ${ }^{1}$, Matheus deA Viúdes ${ }^{1}$, Paula F Rodrigues ${ }^{3}$, Victtoria R Ferreira ${ }^{1}$, Lívia M Rigolon $^{1}$, João MF Assunção ${ }^{1}$ and Aziza Yormirzaeva ${ }^{3}$

${ }^{1}$ Federal University of Juiz de Fora, Brazil

${ }^{2}$ Polyclinic of Botafogo, Brazil

${ }^{3}$ University of Kaiserslautern, Germany

\begin{abstract}
Introduction: Hearing loss is a condition of great impact for the elderly, being the most common sensory deficit in this population. It is known that falling from one's own height is also an important disabling event and that it may be related to several contributing factors. Several studies indicate that hearing problems are strictly related to the increased risk of falls.

Objective: To verify the correlation between hearing loss and episodes of falls in the elderly.

Methods: Descriptive cross-sectional study, carried out on a population sample of 117 individuals aged between 60 and 90 years and who were being followed up at the Health Department for the Elderly, in the city of Juiz de Fora, between 2017 and 2018. Data were collected from questionnaire, otoscopic examination and audiometric evaluation at frequencies of $500 \mathrm{~Hz}$ and $4 \mathrm{KHz}$. Chi-square test was applied and p value less than 0.05 for univariate analysis between hearing loss and falls and associated factors.

Results: Hearing impairment was observed in 23 individuals (19.6\%) and at least one episode of falling by 42 (35.9\%) was described, 7 of which were identified with hearing loss. The association between hearing loss and falls in the sample showed a $\mathrm{p}$ value of 0.84 . As for the association between sex and falls, in the female population $(\mathrm{n}=95)$, falls were reported by $36.8 \%$. In the male population $(\mathrm{n}=22), 31.8 \%$ reported falls. The $\mathrm{p}$-value for gender and falls was 0.84 . In the population that lived unaccompanied $(n=31)$, the presence of falls was $41.9 \%$, with a $\mathrm{p}$ value of 0.55 .
\end{abstract}

Conclusion: There was no statistically significant association between falls and factors such as hearing loss, sex and living together.

\section{Introduction}

Hearing Loss (HL) is a medical condition with a great impact on the health, quality of life and social interaction of the person affected by this disease. It is the most common sensorial deficit in elderly patients, and the deficit related to the aging process is the leading cause of HL worldwide, with a prevalence of $37 \%$ of people between 61 and 70 years and more than $80 \%$ of elderlies above 80 [1]. In 2018, WHO published the following data: 466 million people suffered from HL (the number of cases doubled from the period between 1990 and 2016) [2]. It is estimated that 3 billion US\$ are spent due to $\mathrm{HL}$ and its related problems. Also, it has been noted that there are no gender differences, due to the similar lifestyle between men and women [3]. Unfortunately, it still a underdiagnosed condition, as the cultural belief that $\mathrm{HL}$ is a condition inherent to the ageing process, and the development of the disease can lead to other important problems, such as depression, social detachment, frailty, impaired communication, cognitive issues and falls from standing height [4].

Hearing loss in its peripheral form can be divided into conductive or sensorineural. In conductive hearing loss there is an impairment in the middle or outer ear (due to impacted cerumen), meanwhile in the second case the source is a dysfunction in the inner ear - cochleal deficit per se or in its respective ganglion, due to otosclerosis [5]. In addition to it, $\mathrm{HL}$ is the most important modifiable risk factor for preventing the development of demential diseases [6]. In that scenario, age-related hearing loss (ARHL) typically presents as a progressive, bilateral, symmetrical and sensorineural HL, more pronounced at higher frequencies. It usually starts in the fourth decade, but it is more evident over the age of eighty [7]. It should be noted also that $\mathrm{HL}$ is categorized from slightly to profound, according to the results of audiometric tests: hearing levels impaired thresholds from 16 to $25 \mathrm{~dB}$ are considered slightly; $26-40 \mathrm{~dB}$ is defined as a mild $\mathrm{HL}$; $41-60 \mathrm{~dB}$ is considered moderate; severe from 61 to $80 \mathrm{~dB}$ and profound, when its higher than $80 \mathrm{~dB}$ [8]. According with the World Health Organization approximately one third of people aged 65 years and older are affected by a hearing loss of at least $40 \mathrm{~dB}$ [7].

It is known that falls from standing height is a very prevalent and potentially disabling event among the elder population. Research data from the United States of America shows that approximately 30\% of people above 65 years have at least one episode of fall per year, which brings a lot of suffering to the patient and family, and naturally it elevates the medical expenses in the healthcare system. In 2020 the financial burden due to these accidents is expected to reach US\$ 67.7 billion. Also, it is clear that the first event of falling by an elderly patient is the most important factor leading to another fall episodes [9]. It is important to notice that falls have a lot of contributing factors, such as

*Correspondence to: Natália Baraky Vasconcelos, Polyclinic of Botafogo, Brazil, Tel: +55 21 967703899, E-mail: nataliabaraky@hotmail.com

Key words: hearing loss, hearing impairment, falls, accidental falls, elderly

Received: October 12, 2020; Accepted: November 02, 2020; Published: November 05, 2020 
body weakness, malnutrition, use of medications, cognitive decline and proprioception deficits, which is intrinsically related to HL. Moreover, insufficient balance skills are shown in a wide broad range of symptoms, such as slow walking speed and poor Romberg tests scores [10]. It is also known that HL is a changeable risk factor for fallings, and evidence shows that hearing problems are strictly related to increased fall risks in older adults and in the elderly population, in which the presence of $\mathrm{HL}$ was noted as 2.39 times greater odds for fall episodes [11].

Therefore, in the presence of these context, this study aimed to verify the correlation between HL and fall episodes, and also other correlated factors that may interfere in the hearing problems and falling by the elderly population due to the fact that hearing loss can be easily corrected or diminished.

\section{Objective}

To verify the correlation between hearing loss and episodes of falls in the elderly and other correlated factors.

\section{Methods}

This research was approved by the Research Ethics Committee (61055616.1.0000.5147) and was carried out in a referral center for elderly patients, the Department of Elderly Health. All recruited patients signed the Free and Informed Consent Form.

The data was collected through a descriptive cross-sectional study conducted at the Department of Elderly Health in the city of Juiz de Fora - MG during the period between 2017 and 2018. The sample of this study included people randomly selected, over 60 years old, who were on follow up at the Department of Health for the Elderly, and necessarily agree to sign the Free and Informed Consent Form. Were excluded those who did not agree to participate in the proposed study and/or who did not fill the criteria mentioned above. The sample was composed of only one group: 117 individuals between 60 and 90 years. Interviews were conducted by a structured questionnaire based on the WHO model (1999) with modifications to collect data. It was applied by medical students, under the supervision of an otorhinolaryngologist. The following variables were evaluated through the questionnaire: name, age, date of birth, gender, income, skin color, occupation, marital status, house conditions, health conditions (previous pathologies or hearing impairment), daily medications, history of hospitalizations, occurrence of recent falls (in addition to the number and reason of falls), use of alcohol or tobacco and the amount of people living at the same home. Subsequently, all participants were evaluated through clinical otorhinolaryngological examination (otoscopie) by an otorhinolaryngologist at the Department of Health of the Elderly in Juiz de Fora. The otoscopy examination was performed with the introduction of an otoscope (Otoscope K $100^{\circ} 3.5 \mathrm{~V} \mathrm{~B}-245.20 .376$, Heine, Germany) in the auditory canal, which allows the assessment of the permeability of the external auditory canal, local changes (presence of cerumen, foreign body) and tympanic membrane conditions (signs of infection, perforations). After the clinical evaluation, the participants were submitted to an audiometric evaluation (tonal and vocal audiometry), performed by an otorhinolaryngologist. Both ears were evaluated from $500 \mathrm{~Hz}$ to $4 \mathrm{KHz}$, to identify possible $\mathrm{HL}$ and its respective classification. The classification used to determine HL was the degree, considering individuals without $\mathrm{HL}$ those whose tritone average was up to $25 \mathrm{~dB}$, and with HL those with tritone average $>26 \mathrm{~dB}$ ). The audiometry was performed with a headset, through which the individual could hear pure tones of intensities (loud or weak sounds) and varied frequencies (low or high sounds). This examination depends on the individual's cooperation, therefore the answers given by the individual determine whether hearing is preserved or impaired.

Research questions for statistical study are based on identifying whether there is a statistically significant association between the falls (present or absent) and any of the risk factors: hearing impairment (yes or no), living accompanied (yes or no) and gender (male or female). All variables of interest are qualitative and of dichotomous nature. The data on 117 participants were collected by asking poll questions based on the confounding factors of interest. The corresponding null hypotheses set up for the study are:

1. H_0: there is no statistically significant association between the falls and hearing impairment

2. H_0: there is no statistically significant association between the falls and living accompanied

3. H_0: there is no statistically significant association between the falls and gender

The Chi squared statistic is used to provide answers to the research questions above. The collected data fulfills assumptions of this particular test. The observed and expected values are calculated and the Chi-squared test has been run using the statistical software RStudio (Version1.2.5042). Results are shown in the tables 1-3. All expected values are larger than 5, indicating the Chi-squared statistics appropriateness [12].

For degree of freedom 1 and a 5\% level of significance, the corresponding critical value is 3.841 and the null hypothesis is rejected if the Chi-squared statistic is larger or equal to 3.84 [13].

Table 1. Association between falls and hearing impairment

\begin{tabular}{|c|c|c|c|c|c|}
\hline & & & \multicolumn{2}{|c|}{ HI } & \multirow{2}{*}{ Total } \\
\hline & & & Absence & Presence & \\
\hline \multirow{5}{*}{ Falls } & \multirow{2}{*}{ No } & Observed & 59 & 16 & \multirow{2}{*}{75} \\
\hline & & Expected & 60.26 & 14.74 & \\
\hline & \multirow{2}{*}{ Yes } & Observed & 35 & 7 & \multirow{2}{*}{42} \\
\hline & & Expected & 33.74 & 8.26 & \\
\hline & \multicolumn{2}{|c|}{ Total } & 94 & 23 & 117 \\
\hline \multicolumn{6}{|c|}{$\begin{array}{l}\text { Pearson's Chi-squared test with Yates' continuity correction } \\
X \text {-squared }=0.13, \mathrm{df}=1, \mathrm{p} \text {-value }=0.71\end{array}$} \\
\hline
\end{tabular}

Table 2. Association between falls and gender

\begin{tabular}{|c|c|c|c|c|c|}
\hline & & & \multicolumn{2}{|c|}{ Gender } & \multirow{2}{*}{ Total } \\
\hline & & & Female & Male & \\
\hline \multirow{5}{*}{ Falls } & \multirow{2}{*}{ No } & Observed & 60 & 15 & \multirow{2}{*}{75} \\
\hline & & Expected & 60.90 & 14.10 & \\
\hline & \multirow{2}{*}{ Yes } & Observed & 35 & 7 & \multirow{2}{*}{42} \\
\hline & & Expected & 34.10 & 7.90 & \\
\hline & \multicolumn{2}{|c|}{ Total } & 95 & 22 & 117 \\
\hline
\end{tabular}

Pearson's Chi-squared test with Yates' continuity correction

$\mathrm{X}$-squared $=0.04, \mathrm{df}=1, \mathrm{p}$-value $=0.84$

Table 3. Association between falls and living accompanied

\begin{tabular}{|c|c|c|c|c|c|}
\hline & & & $\begin{array}{c}\text { Living } \\
\text { Accompanied }\end{array}$ & & Total \\
\hline & & & No & Yes & \\
\hline \multirow{5}{*}{ Falls } & \multirow{2}{*}{ No } & Observed & 18 & 57 & \multirow{2}{*}{75} \\
\hline & & Expected & 19.87 & 55.13 & \\
\hline & \multirow{2}{*}{ Yes } & Observed & 13 & 29 & \multirow{2}{*}{42} \\
\hline & & Expected & 11.13 & 30.87 & \\
\hline & \multicolumn{2}{|c|}{ Total } & 31 & 86 & 117 \\
\hline
\end{tabular}

Pearson's Chi-squared test with Yates' continuity correction

$\mathrm{X}$-squared $=0.36, \mathrm{df}=1, \mathrm{p}$-value $=0.55$ 
It can be seen that the p-values for none of these cases are less than 0.05 , which does not allow to reject none of the null hypotheses under investigation. The small difference between the observed and expected values validates this finding.

\section{Results}

Hearing impairment (HI) was found in a total of 23 individuals (19.6\%) versus 94 individuals (80.4\%) in which the hearing impairment was not verified in a number of 117 participants in the present study (Table 1). The degree of hearing loss was not qualified for statistical analysis, considering individuals without $\mathrm{HI}$ those whose tritone average was up to $25 \mathrm{~dB}$, and with $\mathrm{HI}$ those with tritone average $>26 \mathrm{~dB}$. In relation to the reported episodes of falls, the presence of at least one fall was described in $42(35.9 \%)$ individuals versus 75 (64.1\%) individuals without this history. In those patients whose hearing impairment was found $(n=23)$, a total of $7(30.4 \%)$ individuals had reported episodes of falls, while 16 (69.6\%) individuals did not have any episodes, which is expected for this population, respectively, 8.26 and 16 individuals. As for patients without hearing impairment $(n=94)$, a total of $35(37.2 \%)$ individuals with reported episodes of falls were found, while 59 (67.3\%) individuals did not present any episode, which was expected for this population, respectively, 33.74 and 60.26 individuals. The association of impairment $(\mathrm{HI})$ and falls (Table 1 ) showed $\mathrm{X}^{2}=0.04$, p-value $=0.84$, so it is not possible to rule out the null hypothesis 1 , demonstrating that there is no statistically significant relationship between $\mathrm{HI}$ and falls in this study.

The same number of 117 participants was included in the association between gender and falls (Table 2). A total of 95 female individuals $(81.2 \%)$ were counted versus 22 male individuals (18.8\%). Among the female population $(n=95)$, the presence of falls was observed in $35(36.8 \%)$ women, while $60(63.2 \%)$ women did not present any episode, with the expected for this population, respectively, 34.10 and 60.90. Among the male population $(n=22)$, the presence of falls was observed in $7(31.8 \%)$ men, while $15(68.2 \%)$ men did not present any episode, being the expected for this population, respectively, 7.90 and 14.10. The association between gender and falls (Table 2) showed $X^{2}$ $=0.04$, p-value $=0.84$, so it is not possible to rule out null hypothesis 2 , demonstrating that there is no statistically significant relationship between gender and falls in this study.

Finally, the same number of 117 participants was included in the association between accompanied living and falls (Table 3). Has a total of 86 individuals living accompanied (73.5\%) versus 31 unaccompanied individuals (26.5\%). Among the accompanied population $(n=86)$, The presence of falls in $29(33.7 \%)$ individuals, while 57 (66.3\%) individuals did not present any episode, being the expected for this population, respectively, 30.87 and 55.13. Among the unaccompanied population $(\mathrm{n}=31)$, The presence of falls in $13(41.9 \%)$ individuals, while 18 (58.1\%) individuals did not present any episode, being the expected for this population, respectively, 11.13 and 19.87. The association between accompanied living and falls (Table 3 ) showed $\mathrm{X}^{2}=0.36$, $\mathrm{p}$-value $=0.55$, so it is not possible to rule out the null hypothesis 3 , demonstrating that there is no statistically significant relationship between living accompanied and falls in this study.

\section{Discussion}

The HL is the most prevalent sensory deficiency among the elderly, being an impacting factor in the quality of life of people over 60 years of age and may favour the development and worsening of comorbidities such as depressive disorder, frail elderly syndrome and dementia [4].
It was observed that HLA is bilateral, symmetrical, sensorineural and at high frequencies in most cases, and can be reduced or corrected if the approach is carried out in the appropriate manner and at the appropriate time [7].

Falling from one's own height is a disabling event relevant to the population elderly, very related to morbidity and mortality in this age group and which may be associated with a number of factors [9]. It stands out according to the International Classification of Diseases (CID), that accidents due to falls have been an important problem related to morbidity and mortality due to external causes in elderly people. In addition, it generates a great expense for public health due to the expressive need for hospitalizations. For example, according to the most recent published data collected over a five-year period, the number of accidents involving falls in older Brazilians treated at the Brazilian Unified National Health System (SUS) facilities and subsequently hospitalized was 399,681 , costing the Ministry of Health a total of BRL 464,874,275.91 ( $\approx$ USD 138,002,773.85) [1].

Additionally, it is known that the high incidence of falls is multifactorial and can be associated with several pathologies and syndromes typical of the elderly. Thereby, considering the high prevalence of hearing loss among older adults, it is questioned whether hearing impairment could be one of the factors that contribute to increase the risk of falling. Possible explanations for the association between hearing loss and falls include coexistent vestibular pathology that increases fall risk, reduction in cognitive capacity for balance given the cognitive load of hearing loss, and a loss of auditory perception leading to reduced spatial awareness [11].

Concerning the results of this study, as expected, a high prevalence of falls was observed, in which the presence of at least one fall in the last year was described in 42 (35.9\%) of 117 individuals over the age of sixty. These results are consistent with most of the studies analysed, for example a study carried out in the United States that defined that onefifth $[14]$ to one-third $[15,16]$ of older adults are estimated to fall in a 1-year period in the United States [17].

Regarding the association between hearing loss and falls, in this study there was no statistically significant relationship between HI and falls, possibly due to a small number of participants and memory bias. However, a large number of studies have found that $\mathrm{HI}$ increases the risk of falling, including a meta-analysis that found $21 \%$ increased odds of falling among those with HI [18-21]. Other studies concluded that audiometrically defined hearing loss was associated with 2.39 times greater odds of falling [11] and that for every $10-\mathrm{dB}$ increase in hearing loss, there was a 1.4-fold (95\% CI, 1.3-1.5) increased odds of an individual reporting a fall over the preceding 12 months [22].

Although in this study there was no statistically significant relationship between gender and falls or living accompanied and falls, a study raised the possibility that the association between $\mathrm{HI}$ and falls was greater in women than men. Speculatively, this observation may be related to women being more likely to report a fall, experience fallrelated injury, and suffer functional decline following a fall [14,23-25]. Whereas the relationship between living alone and the risk of falls needs to be further explored in the evaluated literature.

This was a cross-sectional study, initially performed to assess the possible association between the number of falls and hearing loss in the city of Juiz de Fora. Therefore, in the future, prospective cohort studies should be performed to further explore the possible causal associations between $\mathrm{HL}$ and episodes of falling and to avoid memory bias for fall events. Also, it is important to include a larger number of participants. 
We emphasize that many are the sensory systems involved in body balance, such as proprioceptive, vestibular, visual, and auditory systems. Therefore, these confounding factors should be considered to assess the real association between isolated hearing loss and the risk of falls.

Lastly more prospective studies are recommended to establish a causal association and overcome a potential positive publication bias in the literature. Also, studies including more comprehensive sensory function tests, such as vestibular function, gait integrity, visual loss and proprioceptive loss must be performed to limit confusion factors related to the occurrence of falls.

\section{Conclusion}

As a result of the analysis of the data in the present study, no statistically significant association was observed between falls and hearing loss. In addition, there was also no relationship between the occurrence of falls and the gender of the patients.

\section{References}

1. Phan NT, McKenzie JL, Huang L, Whitfield B, Chang A (2016) Diagnosis and management of hearing loss in elderly patients. Aust Fam Physician 45: 366-369. [Crossref]

2. Golovanova LE, Boboshko MY, Kvasov EA, Lapteva ES (2019) Hearing loss in adults in older age groups. Adv Gerontol 9: 459-65. [Crossref]

3. Homans NC, Metselaar RM, Dingemanse JG, van der Schroeff MP, Brocaar MP, et al. (2017) Prevalence of age-related hearing loss, including sex differences, in older adults in a large cohort study. Laryngoscope 127: 725-730. [Crossref]

4. Uchida Y, Sugiura S, Nishita Y, Saji N, Sone M, et al. (2019) Age-related hearing loss and cognitive decline-The potential mechanisms linking the two. Auris Nasus Larynx 46: 1-9. [Crossref]

5. Cunningham LL, Tucci DL (2017) Hearing loss in adults. $N$ Engl J Med 377: 24652473. [Crossref]

6. Tu NC, Friedman RA (2018) Age-related hearing loss: Unraveling the pieces. Laryngoscope Investigative Otolaryngol 3: 68-72. [Crossref]

7. Davis A, McMahon CM, Pichora-Fuller KM, Russ S, Lin F, et al. (2018) Aging and Hearing Health: The Life-course Approach. Gerontologist 56: S256-S267. [Crossref]

8. Goman AM, Lin FR (2016) Prevalence of hearing loss by severity in the United States. Am J Public Health 106: 1820-1822. [Crossref]

9. Kowalewski V, Patterson R, Hartos J, Bugnariu N (2018) Hearing loss contributes to balance difficulties in both younger and older adults. J Prev Med (Wilmington) 3. 12. [Crossref]
10. Ballesteros MF, Webb K, McClure RJ (2017) A review of CDC's Web-based Injury Statistics Query and Reporting System (WISQARSTM): Planning for the future of injury surveillance. J Safety Res 61: 211-215. [Crossref]

11. Jiam NT, Li C, Agrawal Y (2016) Hearing loss and falls: A systematic review and meta-analysis. Laryngoscope 126: 2587-2596. [Crossref]

12. McHugh ML (2013) The Chi-Square Test of Independence. Biochemia Medica 23 143-149.

13. Scott, M, Flaherty D, Currall J (2013) Statistics: Dealing with Categorical Data. J Small Anim Pract 54: 3-8. [Crossref]

14. Stevens JA, Ballesteros MF, Mack KA, Rudd RA, DeCaro E, et al. (2012) Gender differences in seeking care for falls in the aged Medicare population. Am J Prev Med 43: 59-62. [Crossref]

15. Hornbrook MC, Stevens VJ, Wingfield DJ, Hollis JF, Greenlick MR, et al. (1994) Preventing falls among community-dwelling older persons: results from a randomized trial. Gerontologist 34: 16-23. [Crossref]

16. Hausdorff JM, Rios DA, Edelberg HK (2001) Gait variability and fall risk in community-living older adults: a 1-year prospective study. Arch Phys Med Rehabil 82: 1050-10105. [Crossref]

17. Criter RE, Honaker JA (2013) Falls in the audiology clinic: a pilot study. $J$ Am Acad Audiol 24: 1001-1005. [Crossref]

18. Deandrea S, Lucenteforte E, Bravi F, Foschi R, La Vecchia C, et al. (2010) Risk factors for falls in community-dwelling older people: A systematic review and meta-analysis Epidemiology 21: 658-668. [Crossref]

19. Kulmala J, Viljanen A, Sipila S, Pajala S, Parssinen O, et al. (2009) Poor vision accompanied with other sensory impairments as a predictor of falls in older women. Age Ageing 38: 162-167. [Crossref]

20. Pluijm SM, Smit JH, Tromp EA, Stel VS, Deeg DJ, et al. (2006) A risk profile for identifying community-dwelling elderly with a high risk of recurrent falling: Results of a 3-year prospective study. Osteoporos Int 17: 417-425. [Crossref]

21. Tromp AM, Smit JH, Deeg DJ, Bouter LM, Lips P (1998) Predictors for falls and fractures in the Longitudinal Aging Study Amsterdam. J Bone Miner Res 13: 19321939. [Crossref]

22. Lin FR, Ferrucci L (2012) Hearing Loss and Falls Among Older Adults in the United States. Arch Intern Med 172: 369-371. [Crossref]

23. Kamil RJ, Betz J, Powers BB, Pratt S, Kritchevsky S, et al. (2016) Association of Hearing Impairment With Incident Frailty and Falls in Older Adults. J Aging Health 28: 644-660. [Crossref]

24. Centers for Disease Control and Prevention (2008) Self-reported falls and fall-related injuries among persons aged $>$ or $=65$ years-United States, 2006. Morbidity and Mortality Weekly Report 57: 225-229.

25. Stel VS, Smit JH, Pluijm SM, Lips P (2004) Consequences of falling in older men and women and risk factors for health service use and functional decline. Age Ageing 33 : 58-65. [Crossref]

Copyright: (C2020 Baraky LR. This is an open-access article distributed under the terms of the Creative Commons Attribution License, which permits unrestricted use, distribution, and reproduction in any medium, provided the original author and source are credited. 